Portland State University

PDXScholar

5-4-1988

\title{
Effects of Graded and Steady Exercise and Self- Confidence on Stress
}

Kristine M. Clarke

Portland State University

Follow this and additional works at: https://pdxscholar.library.pdx.edu/open_access_etds

Part of the Physiology Commons, and the Psychology Commons

Let us know how access to this document benefits you.

\section{Recommended Citation}

Clarke, Kristine M., "Effects of Graded and Steady Exercise and Self-Confidence on Stress" (1988).

Dissertations and Theses. Paper 3758.

https://doi.org/10.15760/etd.5643

This Thesis is brought to you for free and open access. It has been accepted for inclusion in Dissertations and Theses by an authorized administrator of PDXScholar. Please contact us if we can make this document more accessible: pdxscholar@pdx.edu. 
AN ABSTRACT OF THE THESIS OF Kristine Marie Clarke for the Master of Arts in Psychology presented May 4, 1988.

Title: Effects of Graded and Steady Exercise and Self-confidence on stress.

APPROVED BY THE MEMBERS OF THE THESIS COMMITTEE:

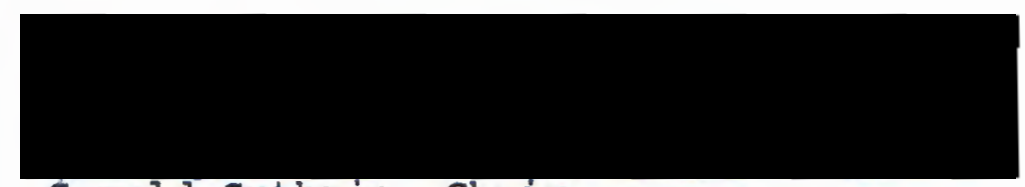

Gerald Guthrie, Chair
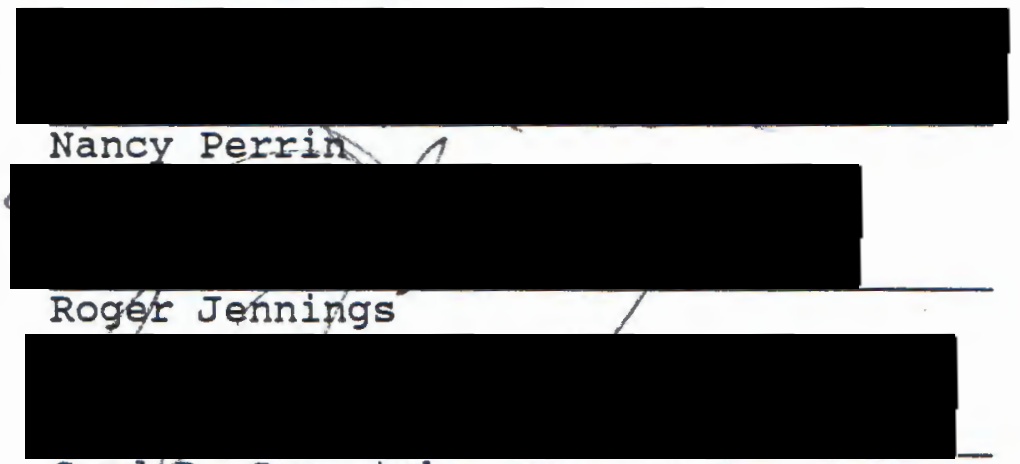

Cord $B$. Sengstake

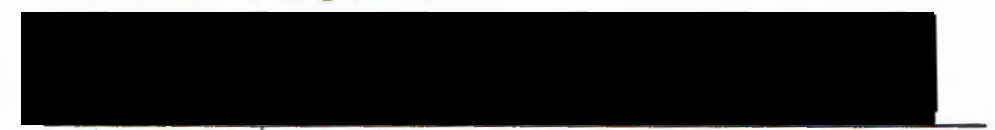

Robert Bqustad

This study examined the effects of steady, graded, and no exercise on stress reduction, and the effects of self-confidence on stress reduction through exercise. Seventy-two male and female volunteers from the Portland area, ranging in age from 19-49 years, served as subjects. 
Subjects completed pre and post measures of the Tennessee Self-Concept scale and the state portion of the spielberger State-Trait Anxiety Inventory. Subjects were divided into two experimental and one control group matched according to age and exercise history. The control group kept its exercise at a minimum for eight weeks. Exercise programs for the two experimental groups consisted of twelve minute work bouts on ergometers three times per week, for eight weeks. Work bouts were at a seventy percent maximum heart rate. Due to attrition and a random drop of subjects in the control group, thirty-one subjects remained. Analyses found a significant stress reduction for the steady exercise group $(t=-2.81, p=.017)$, but not for the graded or no exercise group. Stress reduction was negatively correlated with self-confidence, though not significantly, and no significant differences were found between the self-confidence scores. A significant correlation was found between pre-stress scores and preself-confidence scores $(r=-.306, p=.04)$. 


\title{
EFFECTS OF GRADED AND STEADY EXERCISE \\ AND SELF-CONFIDENCE ON STRESS
}

\author{
by
}

KRISTINE M. CLARKE

A thesis submitted in partial fulfillment of the requirements of the degree of

MASTER OF ARTS

in

PSYCHOLOGY

Portland State University

1988 
TO THE OFFICE OF GRADUATE STUDIES:

The members of the comittee approve the thesis of Kristine Marie Clarke presented May 4, 1988.

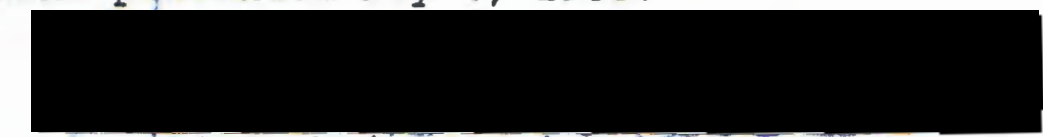

Gerald Guthrie, Chair

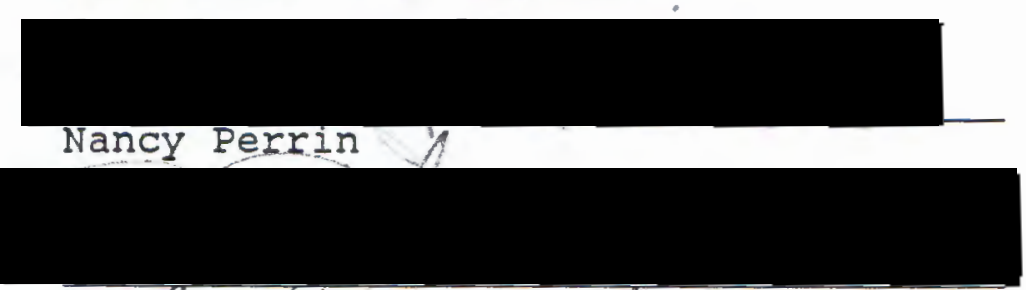

Rogeq Jeninings

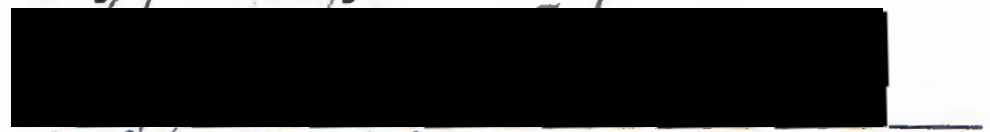

Cordl $\mathrm{B}$. Sengstake

APPROVED:

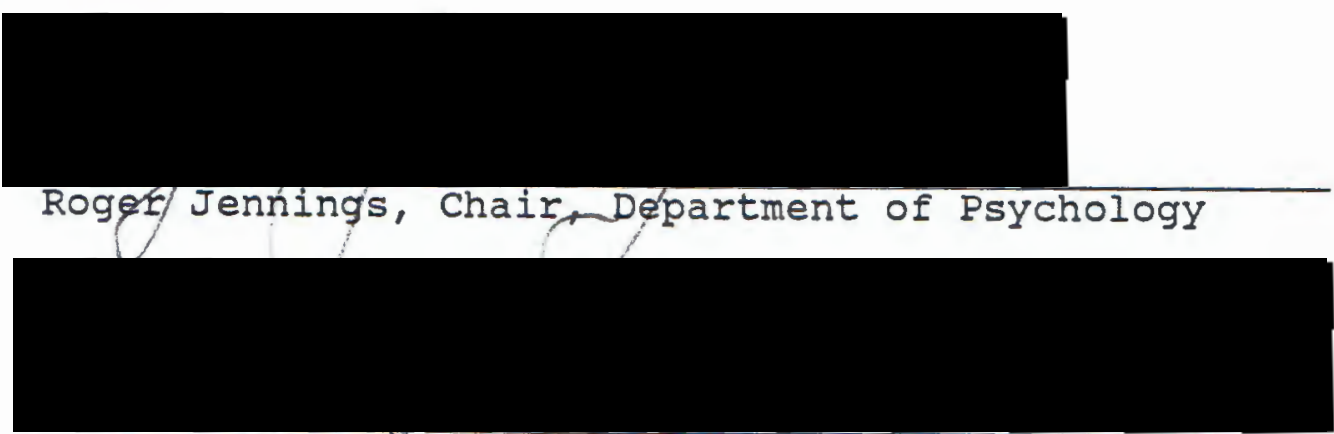

Bernard Ross, Vice Provost for Graduate studies 
TABIE OF CONTENTS

PAGE

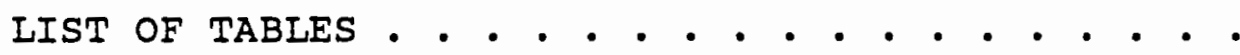

CHAPTER

I REVIEW OF THE LITERATURE . . . . . . . . . 1

Exercise and Stress . . . . . . . . 1

Graded vs Steady Exercise . . . . . . 3

Self-Confidence . . . . . . . . . 7

Hypotheses . . . . . . . . . . 8

II METHOD . . . . . . . . . . . . . . . . . 9

subjects . . . . . . . . . . . 9

Materials . . . . . . . . . . 9

Procedure . . . . . . . . . . 10

III RESULTS . . . . . . . . . . . . . . . 13

IV DISCUSSION • . . . . . . . . . . . • . 16

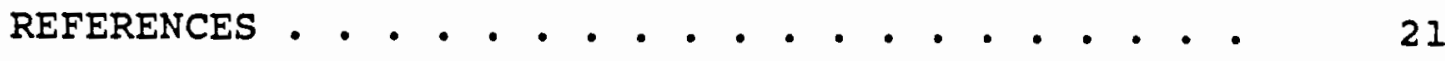




\section{IIST OF TABLES}

\section{TABLE}

PAGE

I Assignment of subjects to Groups . . . . . . 10

II Mean Stress Scores \& Mean Self-Confidence

scores . . . . . . . . . . . . . . . . 
CHAPTER I

REVIEW OF THE IITERATURE

Since Hans Selye's work in 1956, stress and stress management have become major areas of research. Because stress can lead to illness and sometimes death, keeping stress at optimal levels is important. Two types of stress measurements, physiological and psychological, have both been widely used in past research. Physiological measures of stress have included blood pressure, heart rate, and muscular tension. Psychological stress measures have included depression, anger, state anxiety, and trait anxiety.

\section{Exercise and stress}

Exercise is a popular stress reducer and research has confirmed that it is effective. Evidence exists showing that habitual physical exercise and low blood pressure are related (Montoye, Metzner, Keller, Johnson, \& Epstein, 1972). In addition to lowered blood pressure, exercise has been found to reduce other stress indicators such as heart rate, depression, and anger (Hull, Young, \& Ziegler, 1984). Comparing aerobically fit individials (those who could spend the most time on a treadmill at $90 \%$ or more of their 
maximum heart rate before feeling exhausted) to aerobically unfit individuals, heart rate, depression, and anger were lower in the fit individuals. Mihevic (1982) reports a study done by DeVries using muscular tension as a measure of anxiety. Interested in the effects of long term exercise on anxiety, DeVries found that 5-10 weeks of exercise training led to a significant tension decrease.

Exercise has been shown to produce significant reductions in both trait (enduring disposition) and state (a situational, short term factor) anxiety (Lion, 1978; Mihevic, 1982; Andres, Metz, \& Drash, 1978). Using Spielberger's state-Trait Anxiety Inventory (STAI), a measure of trait anxiety, Lion (1978) found that a jogging program of 1 mile a day, 3 times a week, for 2 months, significantly reduced measures of trait anxiety. Measuring both state anxiety and psychological tension, Mihevic (1982) reports a study done by Kowal, Patton, and Vogel which demonstrated that measures of state anxiety and tension were significantly lower in men after 6 weeks of "basic training". Andres, Metz, and Drash (1978) measured state anxiety using the STAI, and found that treadmill work at $70 \%$ of age-related maximum heart rate (MHR) for 20 minutes significantly reduced measures of state anxiety. Finally, several investigations have demonstrated that exercise, when done with enough intensity, will reduce stress (Mihevic, 1982). Mihevic discusses several studies 
done by Morgan using the STAI as a measure of state anxiety. Interested in the effects of short term exercise on anxiety, Morgan has found significant decreases of anxiety in individuals who walk and run on a treadmill to exhaustion at $80 \%$ of their maximum aerobic power (MAP). These effects were also significant with a treadmill walk and run to exhaustion at $100 \%$ MAP. No significant effects were found with light exercise of a I mile treadmill walk (3.5 mph) at 0 or $5 \%$ grade.

\section{Graded vs steady Exercise}

The effects of exercise on stress are clear. Exercise does reduce common indicators of stress, ranging from such physical symptoms as blood pressure, heart rate, and muscular tension to more psychological measures such as depression, anger, state anxiety, and trait anxiety. Some questions concerning the best type of exercise for stress reduction have been explored. Stress may be influenced differently depending upon whether steady exercise (stable output of energy) or graded exercise (progressive increase of energy output) is employed.

Haskell \& Superko (1984) have found that steady, nonprogressive moderate (50-70\% MAP) intensity long term exercise is significantly related to a decrease in coronary heart disease. No greater effects were shown by higher intensity exercise. Berger and owen (1983) have found that 
long term steady exercise consisting of a 40 minute, 2 per week, 14 week exercise program produces significant mood changes as measured by the Profile of Mood Survey (POMS). Boyer and Kasch (1970) also have shown significant results utilizing a steady long term exercise program of a walk-jog type at an intensity of $60 \%$ to $70 \% \mathrm{HR}, 2$ days per week, resulting in a significant drop in diastolic blood pressure.

In contrast, sinyor, Schwartz, Peronnet, and Brisson (1983) have found significant stress reduction effects utilizing graded exercise. They report a significant difference in levels of anxiety using the STAI after graded exercise (a I minute warm up with no resistance, pedaling at $50 \mathrm{rpm}$ on a bicycle ergometer, and at increasing loads of $300,600,900,1200,1500$ KPM). Blumenthal, Williams, Williams, and Wallace (1980) also have found that graded treadmill exercise up to $75 \%$ of the subject's maximum workload over a ten week period significantly reduced measures on the Jenkins Activity Survey (which classifies persons as type $A$ or $B$ ) of those persons classified as having a type A (coronary prone) behavior pattern. Using a short term graded exercise program of pedaling 30 minutes on a bicycle ergometer (4 intervals: first was a 12 minute warm up with a target HR of 90-105 bpm, the next 3 steps progressively increased to target HRs of 105-120 bpm, 120$135 \mathrm{bpm}$, and finally $150 \mathrm{bpm}$ ), Balog (1983) found no 
significant effects measuring muscle tension using EMG measurements. She suggests however, that although graded work may not reduce tension, steady exercise may show different results (Balog notes studies by DeVries who obtained significant results using steady exercise).

Balog's suggestion should be taken with caution since she did not include a comparison of steady and graded exercise. This is also true of the other studies (which all had significant results) previously mentioned. The present study is designed to allow a direct comparison. In doing so, the question of which form of exercise is more effective at reducing stress can be answered. In order to understand how exercise can reduce stress levels, approaches have been considered both from physiological and psychological perspectives. The specific psychological mechanisms through which stress may be reduced using exercise needs to be examined.

The psychological mechanism(s) responsible for the reduction of stress as a result of exercise are not well established. Some of the more popular explanations include:

1) a "time out" principle (Bahrke and Morgan, 1978), whereby taking time out from activities that may be causing some unnecessary stress is sufficient in itself in reducing anxiety; 
2) a process whereby exercise provides a distraction or diversion from stressful events (Bahrke \& Morgan, 1978; Morgan, 1979; Selye, 1976);

3) a cognitive restructuring (Muller \& Armstrong, 1975 ) and counterconditioning (Orwin, 1973\& 1974) process whereby events associated with stress become associated with exercise;

4) a development of mastery through exercising such that succeeding at the exercise task gives a person a sense of having control, which is then associated with a sense of well-being (Ismail \& Trachtman, 1973; Solomon \& Bumpus, 1978); and

5) a process of meditation, which triggers an altered state of consciousness (Buffone, 1980; Solomon \& Bumpus, 1978).

Though there are many psychological theories explaining the relationship between exercise and stress, and though it is difficult to know at this time which is the most accurate, some theories probably deserve more focus than others. Though the "time out" principle may intuitively work, it does not explain why so much attention has been given specifically to exercise as a means of reducing stress when any "time-out" activity might do as well with less effort. This is also true for the diversion and cognitive restructuring and counterconditioning explanations. On the other hand, because of the inherent 
nature of some effort needed for the mastery and meditation principles to work, the role of these psychological processes in reducing stress via exercise is more easily understood. Which of these psychological mechanisms may be responsible is not clear, but it is clear that psychological processes are available in explaining the stress reduction-exercise relationship.

\section{Self-Confidence}

In addition to a steady or graded type of exercise being an important factor in reducing stress, some researchers suggest levels of self-confidence may have an important influence on the effectiveness of exercisereducing stress. Bandura (1977) has argued that a feeling of self-efficacy is a critical mediator of therapeutic improvement. Similarly, the self-confidence that one has in oneself may be a critical factor in the stress-exercise relationship. Haskell and superko (1984) suggest, without benefit of data, that exercise will significantly reduce stress if the person has confidence in achieving success. Driscoll (1976) supports this notion with research that shows that the combination of physical exertion and positive images (which includes a high degree of confidence) produces significant anxiety reduction. The interaction of self-confidence and exercise in stress reduction needs to be examined. 
Hypotheses

The purpose of this study was to investigate the effects of steady versus graded exercise on stress reduction. It was hypothesized that there would be a significant difference between pre-measures and postmeasures of stress, with steady exercise reducing stress more effectively than graded exercise as suggested by Balog. In addition, it was also hypothesized that selfconfidence and stress reduction would be correlated such that as self-confidence increases, so does stress reduction. 
CHAPTER II

METHOD

\section{Subjects}

Seventy-two male and female volunteers ranging in age from 19 to 49 years, served as subjects. Subjects were obtained through announcements and advertisements at a nearby college.

\section{Materials}

The experiment was conducted at a health club. The Tennessee self-Concept Scale, shown to be high in construct validity and reliability (Fitts, 1965), was used to measure the level of seif-confidence of each subject. This test is easily available and it measures types of self-confidence, such as self satisfaction, physical self esteem, personal self, behavior, moral-ethical self, family self, and social self. It also gives a total self-confidence score. The state portion of the Spielberger state-Trait Anxiety Inventory (Spielberger, Gorsuch, \& Lushene, 1970) was used to obtain pre-measures and post-measures of stress for each subject. This test has been shown to be valid and reliable (Spielberger, 1972) and allows comparison with a large number of other studies. Twelve bicycle ergometers were used by the subjects. 


\section{Procedure}

The design of this study included taking pre-measures (PRE) and post-measures (POST) of stress on subjects with varying self-confidence who participated in either a graded, steady, or no exercise program. Thus three groups were analyzed: a graded exercise group with pre and postmeasures of stress, a steady exercise group with pre and post-measures of stress, and a no exercise group with pre and post-measures of stress.

\section{TABLE 1}

ASSIGNMENT OF SUBJECTS TO GROUPS

$\begin{array}{rll} & \text { PRE } & \text { POST } \\ \text { Steady } & 24 \mathrm{Ss} & 24 \mathrm{Ss} \\ \text { Graded } & 24 \mathrm{Ss} & 24 \mathrm{SS} \\ \text { No-exercise } & 24 \mathrm{Ss} & 24 \mathrm{Ss}\end{array}$

After signing a consent form and a medical clearance form, the subjects completed the two questionnaires to establish level of stress and level of self-confidence. In addition, information regarding exercise history and enjoyment of exercise was collected from each subject. In the report of exercise history, each subject listed the average time spent exercising per week during the last six months. Enjoyment of exercise was rated on a scale of 1 to 10, 10 being the most enjoyable for exercise in general. 
The subjects were assigned to one of the three exercise groups. Thus, each group had 24 subjects and the assignment of subjects to the groups was based on a matched distribution according to age and exercise history. Due to attrition, where a majority of the subjects quit the experiment in the first three weeks of the exercise program, 27 subjects were dropped, leaving 45 subjects. subjects in the no exercise group were asked to keep their exercise at a minimum for 8 weeks. Each program for the steady and graded exercise groups consisted of 3 weekly work bouts (Lion, 1978) of 12 minutes each (the ergometers are programmed at $12 \mathrm{~min}$ ) over an 8 week period (Mihevic, 1982; Iion, 1978) with short warm-up and warm-downs before and after each bout. After computing the age-related working heart rate (WHR) (WHR at $70 \%=(220$ - age - resting heart rate (RHR) ) 70\% + RHR, Karvonen, 1959) for each subject $(70 \%$ was chosen due to significant findings of stress reduction from the works of Andres, Metz, \& Drash, 1978; Boyer \& Kasch, 1970; and Haskel1 \& Superko, 1984), those in the steady exercise group began a program in which they rode a bicycle ergometer at low resistance at a speed which maintained their heart rate at a $70 \%$ WHR level. Subjects measured their own heart rate at 4 minutes into each bout and then 5 minutes later. For those in the graded exercise program, each subject was assessed and assigned to a suitable level on an ergometer which would 
entail progressive exercise. This suited level of exercise was determined for each subject and was assigned according to what level of the ergometer lead to an average $70 \%$ WHR level which was determined at the onset of the exercise program. Had a subject not reached his or her average $70 \%$ WHR level during a work bout, the next higher level of the ergometer was used beginning at the next session. In addition, each subject recorded his/her own recovery heart rate (time it takes to return to resting heart rate) after each bout. After 8 weeks of treatment, subjects from the three groups were again tested with the state Anxiety Inventory to assess levels of stress. In addition, the Tennessee Self-Concept scale was readministered. 
CHAPTER III

\section{RESUITS}

Due to an attrition of 27 subjects in the exercise groups and a random drop of 14 subjects from the no exercise group needed to equalize the groups for analysis, a total of 41 subjects were dropped $(\underline{N}=31)$. Thus, the sizes of the no exercise, graded exercise, and steady exercise groups were 10, 9, and 12, respectively. No significant differences between the pre-total selfconfidence scores among the 3 groups were found. There were also no differences between the pre-stress scores among the three groups. Therefore, at the onset of the experiment, the 3 groups did not siffer significantly in either self-confidence or stress. There were no significant differences found between the pre and post self-confidence scores (total or sub-scales). Therefore, only the pre-total self-confidence scores were used to analyze the data. The following table illustrates the differences among the 3 groups, including group size, pre and post-mean stress measures, their standard deviations, average stress reduction, pre-total self-confidence scores, and their standard deviations. 
TABLE II

MEAN STRESS SCORES \& MEAN SELF-CONFIDENCE SCORES GROUP MEASURES

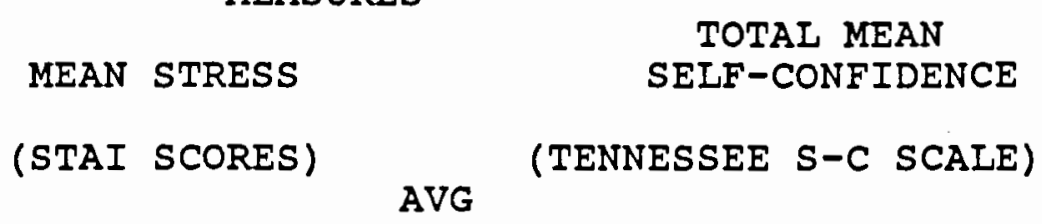
PRE SD POST SD REDUCT PRE-SC SD

NO

$\begin{array}{llllllll}\text { EXERCISE } & 41.4 & 7.18 & 40.9 & 9.07 & .50 & 264.6 & 11.13\end{array}$ $\underline{n}=10$

$\begin{array}{llllllll}\text { GRADED } & 34.0 & 8.2 & 30.89 & 9.79 & 3.11 & 260.67 & 10.92\end{array}$ $\underline{n}=9$

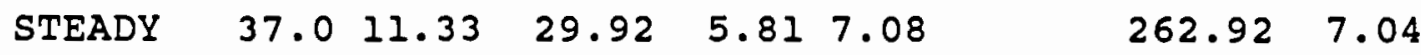
$\underline{n}=12$

The one-way analysis of covariance and subsequent post hoc tests found a significant difference in stress reduction between the steady exercise group and the no-exercise group $(t(20)=2.41, p=.023)$ when the pre-measures of selfconfidence are controlled. However, if pre-self-confidence is not controlled, there are no significant differences in the amount of stress reduction between the three exercise groups. To investigate these findings further, a series of multiple regressions were done.

1) A multiple regression with pre-self-confidence and exercise whereby exercise was dummy coded, found that exercise and pre-self-confidence account for a significant amount of variance in stress reduction $(25 \%)(F(3,27)=3.07, \mathrm{p}=.047)$. 
2) Self-confidence alone accounts for 10.98 of variance, but this is not significant.

3) Exercise group alone accounts for $14.5 \%$ of variance in stress reduction. This is also not significant, although the regression weight of the dummy coded variable comparing the steady and no exercise groups is significant even though the overall model is not. For clarity, simple t-tests were used and only the steady exercise group had a significant stress reduction $(t(22)=2.81, p=.017)$.

The prediction that stress reduction and selfconfidence would be positively correlated was not supported by the data. In fact, the obtained correlation was in the negative direction $(r=-.306)$, although not significantly. Further investigation found a significant correlation between pre-stress scores and pre-self-confidence scores $(r=.365, p=.04)$. Another multiple regression was done to predict stress reduction from the five pre-selfconfidence scores. This was not significant. There was also no correlation between enjoyment of exercise and stress reduction $(r=.008)$. There was also no difference between groups in age or exercise history of the dropped subjects. 


\section{CHAPTER IV}

\section{DISCUSSION}

These findings reveal results which both support and contradict the predictions. Contrary to expectations, the amount and type of graded exercise utilized in this study does not appear to significantly reduce stress. This is not in congruence with previous research. However, steady exercise alone does appear to significantly reduce stress. This agrees with the prediction. In addition, by looking at the results of the sample means, it is clear that graded exercise does have a larger mean stress reduction than no exercise, and steady exercise has a larger mean stress reduction than graded exercise. While these results are not significant, the differences are in the predicted direction. Should these sample means reflect the population means, then the following should be considered. An important issue that may be affecting the significance of these trends is the attrition in this study. More than half of the subjects did not complete their part of the exercise programs. It may be that these people are the ones who would benefit most using exercise as a tool to reduce stress. This seems especially plausible since 
several comments made by those who did not complete their exercise programs were in some way related to their being too busy. It makes intuitive sense that a busy schedule can be stressful in itself. Therefore, these people may have higher levels of stress and may also experience greater stress reduction benefits over those who did complete their exercise programs in this study. In an attempt to cut down on such a high attrition rate, perhaps some type of reinforcement (more than a simple recording of recovery heart rates as done in this study) could be used to keep subjects in future studies of this type. In addition, at the onset of the experiment, the no exercise subjects were asked to keep their exercise at a minimum. However, no effort was made to find out whether or not the subjects complied. It is possible that some subjects engaged in more than a minimum of exercise, thus masking the differences between control \& experimental groups. Future research needs to keep this point in mind.

In contrast to the predicted relationship between self-confidence and stress reduction, the findings suggest that self-confidence and stress reduction are uncorrelated, and in fact, have an inverse relationship with low selfconfidence associated with high stress reduction. If the tendency of this data is reflective of the population, then there are several alternative explanations. First, the subjects in this study were obtained 
through classroom announcements at a nearby college. There may be something about college students, such as a tendency towards higher self-confidence, or towards well-balanced scores on the sub-scales of self-confidence, that makes this sample uncharacteristic of the general population. Therefore, future research needs to seek subjects of more diverse self-confidence levels.

It also seems from the results that self-confidence and exercise group do not have much variance in common in this study. In addition, there is a significant correlation between pre-stress scores and pre-selfconfidence scores. Therefore, it is suggested that future research control the stress self-confidence exercise group relationship at the experimenter level. This could easily be done by testing for stress and self-confidence and then evenly distributing subjects to their groups according to these scores in addition to an equal distribution of subjects to groups balanced according to age and exercise history.

Also, future research is needed to clarify the relationship between stress reduction and self-confidence, especially since very little research has been done in this area. Previous research mentioned in the introduction suggests that high self-confidence persons should show the greatest stress reduction using exercise. However, in this study, pre-stress measures are positively correlated to 
pre-self-confidence. Perhaps people with high selfconfidence feel capable of dealing with stress, and thus enter into situations which involve higher levels of stress. Furthermore, maybe they like this stress and thus strive to maintain its high level. This, then, would explain why high self-confidence subjects had less stress reduction effects than low self-confidence subjects. The high self-confidence subjects were possibly trying to maintain their high level of stress. More research is needed to clarify this issue of self-confidence and exercise. Such a study could include subjects with varied levels of stress and self-confidence who are placed in the three exercise groups used in this study. This would enable a look at how exercise affects different levels of stress and self-confidence.

In addition for a need to lower attrition, obtain more diverse self-confidence subjects, control the stress-selfconfidence-exercise group relationship at the experimenter level, and analyze the effects of exercise on different levels of stress and self-confidence, future research may wish to test other kinds of steady exercise and graded exercise. Furthermore, physiological measures of stress may be included in order to gain more information about the exercise -stress -self-confidence relationship.

once again, note that many different psychological mechanisms are available which explain how exercise can 
reduce stress. As mentioned earlier, these mechanisms include the "time-out" principle, the distraction/diversion principle, the cognitive principle, the mastery principle, and the meditation principle. Nothing in the results of this study can clarify which of these mechanisms is at work. It may be that a combination of these psychological principles may explain how stress is reduced through exercise. The "time-out", distraction/diversion, and the cognitive theories do not explain the wide use of exercise as a stress reduction tool, when activities with less effort can be used. The mastery and meditation principles cannot function without, at least a small amount of effort involved. These latter two mechanisms deserve more research focus, either separately or combined, as explanations for stress reduction through exercise.

It appears that steady exercise may be a useful tool in reducing stress. If the data from this sample replicate those of the population, this may be especially true for those with lower self-confidence Future research ideas are offered which may clarify and support the results found in this study. 


\section{REFERENCES}

Andres, F.F., Metz, K.F., and Drash, A.L. (1978). Changes in state anxiety and urine catecholamines produced during treadmill running. Medicine and science in sports, 10, 51 .

Balog, L.F. (1983). The effects of exercise on muscle tension and subsequent muscle relaxation training. Research Quarterly for Exercise and sport, 54, 2, $119-125$.

Bahrke, M.S., \& Morgan, W.D. (1978). Anxiety Reduction following exercise and meditation. Cognitive Therapy and Research, 2, 323-334

Berger, B.G., \& Owen, D.R. (1983). Mood alteration with swimming- swimmers really do "feel better". Psychosomatic Medicine, 45, 5, 425-433.

Blumenthal, J.A., Williams, S., Williams, R.B., \& Wallace, A.G. (1980). Effects of exercise on Type A (coronary prone) behavior pattern. Psychosomatic Medicine, 42, 289-296.

Boyer, J.I. \& Kasch, F.W. (1970). Exercise therapy in hyperextensive men. Journal of the American Medical Association, 211, 1668-1671.

Buffone, G.W. Exercise as Therapy: A closer look. (1980). Journal of counseling and Psychotherapy, 3, 101-115

Driscoll, R. (1976). Anxiety reduction using physical exertion and positive images. The Phsychological Record, 26, 87-94.

Fitts, W. (1965). Manual for the Tennessee selfConcept Scale. Nashville, Tennessee: Counselor Recordings \& Tests.

Haskell, W.L., \& Superko, R. (1984). Designing an exercise plan for optimal health. Family \& Community Health, 7, 72-88. 
Hull, E.M., Young, S.H., \& Ziegler, M.G. (1984). Aerobic fitness effects cardiovascular and catecholamine responses to stressors. Phsychophysiology, 21, 3, 353-360.

Ismail, A.H., \& Trachtman, L.E. (1973). Jogging the imagination. Psychology Today, 3, 79-82.

Karvonen, M.W. (1959). Effects of vigorous exercise on the heart, in Rosenbaum, F.F., and Belknap, E.L. (eds). Work and the Heart, New York: Paul B. Hoebner, Inc.

Lion, L.S. (1978). Psychological effects of jogging: A preliminary study - Perceptual and Motor skilis, 47, 1215-1218.

Mihevic, P.M. (1982). Anxiety, depression, and exercise. Quest, 33, 2, 140-153.

Montoye, H.J., Metzner, H.C., Keller, J.B., Johnson, B.C., \& Eptstein, F.H. (1972). Habitual physical activity and blood pressure. Medicine \& Science \& Sports, 4, 175-181.

Morgan, W.P. (1979). Anxiety reduction following acute physical activity. Psyciatric Annals, 9, 141-147.

Muller, B., \& Armstrong, H.E. (1975). A further note on the "running treatment" for anxiety. Psychotherapy: Theory, Research and Practice, 12, 385-387.

Orwin, A. (1973). 'The running treatment': A preliminary communication on a new use for and old therapy (physical activity) in the agoraphobic syndrome. British Journal of Psychiatry, 122, 175-179.

Orwin, A. (1974). Treatment of a situational phobia- A case for running. British Journal of Psychiatry, 125 , 95-98.

Selye, H. (1956). The Stress of Life. New York: MCGraw-Hill.

Selye, H. (1976). Stress and Physical activity. McGill Journal of Education, 11, 3-14.

Sinyor, D., Schwartz, S.G., Peronnet, F., Brisson, G., \& Seraganian, P. (1983). Aerobic fitness level and reactivity to psychological stress: Phsysiological, biochemical, and subjective measures. Psychosomatic Medicine, 45, 205-217. 
Solomon, E.G., \& Bumpus, A.K. (1978). The running meditation response: An adjunct to psychotherapy. American Journal of Psychotherapy, 32, 583-592.

Spielberger, C.D., Gorsuch, R.L., \& Lushene, R.E. (1970). Manual for the state-Trait Anxiety Inventory. Palo Alto, California: Consulting Psychologist Press.

Spielberger, C.D. (1972). Anxiety: Current Trends in Theory and Research. New York and London: Academic Press. 